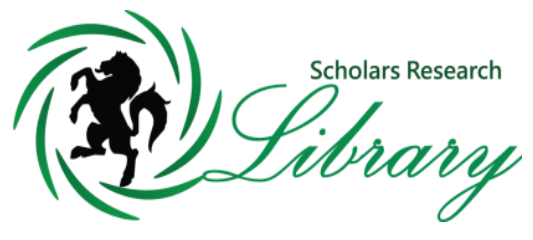

Scholars Research Library

Der Pharmacia Lettre, 2016, 8 (15):73-78

(http://scholarsresearchlibrary.com/archive.html)

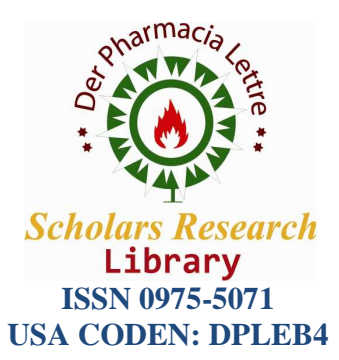

\title{
Optimization of Spirulina Platensis Culture for Antioxidant Production
}

\author{
Zulkarnain Chaidir $^{1}$, Desi Nurakbari ${ }^{2}$, Marniati Salim $^{3}$ and Rahadian Zainul ${ }^{4}$ \\ ${ }^{1-3}$ Department of Chemistry, Universitas Andalas, Padang, Indonesia \\ ${ }^{4}$ Department of Chemistry, Universitas Negeri Padang, Indonesia
}

\begin{abstract}
Spirulina platensis is a unicellular microalgae that has high nutritional value such as proteins, carbohydrates, lipids and carotenoids like $\beta$-carotene. The microalgae rapidly grows in Bold Bassal Medium modification and high intensity of light. The aims of this research were to optimize the culture growth and determine antioxidant activity of S. platensis. Culture was optimized by adding urea and $\mathrm{NaHCO}_{3}$ I nto the medium and applying dark: light period $(12: 12 \mathrm{~h} / \mathrm{h})$ under solar or fluorescent light (3000 lux). The optimum growth of Spirulina platensis was in 0,3 g/L urea, pH 9 at fluoresense light (3000 lux). Antioxidant acivity of various spirulina extract was studied by 1,1diphenyl-2-picryl-hydrazyl (DPPH) free radicals scavenging method. The Spirulina radicals scavenging activity of acetone : methanol (1:1) extract was 46,39\%. The acetone:methanol (1:1) extract showed better antioxidant activity than acetone extract. The $\beta$-carotene was determined using HPLC in a silica gel column with dichloromethane, acetonitrile, methanol $(20: 70: 10, v / v / v)$ as a mobile phase. The acetone extract displayed the highest sample area and produced $1.32 \%$ of $\beta$-carotene out of total biomass.
\end{abstract}

Keywords : Spirulina platensis, antioxidant, free radical, HPLC, DPPH

\section{INTRODUCTION}

Free radicals area highly unstable molecule that containing one or more unpaired electrons in atomic or molecular orbitals [1]. Free radicals also known as reactive oxygen species [ROS] or reactive nitrogen species [RNS]. ROS may lead to stimulation of inflammatory process, secretion of chemotactic factors, growth factors, proteolytic enzymes, lipoxygenases, and cyclooxygenases, inactivation of antiproteolytic enzymes and activation of oncogenes and transcription factors [2]. Free radicals may come from cigarette smoke, air pollution, and sunlight that can causes "oxidative stress" a process that can trigger cell damage. Oxidative stress is thought to play a role in a variety of diseases including cancer, cardiovascular diseases, diabetes, Alzheimer's disease, Parkinson's disease, and eye diseases such as cataracts and age-related macular degeneration [3-7].

Proteins are the major targets for ROS because of their high overall abundance in biological systems. Since proteins are primarily responsible for most of cell activities, their peroxidative damage by ROS is particular importance. It has been estimated that proteins can scavenge the majority [50\%-75\%] of reactive species generated [8].In order to reduce free radicals damage to the human body, synthetic antioxidants are used for industrial processing at the present time. However, the most commonly used of synthetic antioxidant has been suspected of being responsible for liver damage and carcinogenesis [2]. This is essential to develop and utilize effective and natural antioxidants that can protect the human body from free radicals and retard the progress of many chronic diseases.

To protect cells and organ systems of the body against reactive oxygen species, humans have evolved a highly sophisticated and complex antioxidant protection system. It involves a variety of components, both endogenous and exogenous in origin, that function interactively and synergistically to neutralize free radicals [9]. 


\section{These components include:}

1. Nutrient-derived antioxidants like carotenoids including $\beta$-carotene, ascorbic acid (vitamin C).

2. Tocopherols and tocotrienols (vitamin E), and other low molecular weight compounds such as glutathione and lipoic acid.

3. Antioxidant enzymes, e.g.superoxide dismutase, glutathione peroxidase, and glutathione reductase, which catalyze free radicals quenching reactions.

4. Metal binding proteins, such as ferritin, lactoferrin, albumin, and ceruloplasmin that sequester free iron and copper ions that are capable of catalyzing oxidative reactions.

5. Numerous other antioxidant phytonutrients present in a wide variety of plant foods.

Vitamin $\mathrm{C}$, vitamin $\mathrm{E}$, and $\beta$-carotene are among the most widely studied dietary antioxidants [10]. $\beta$-carotene and other carotenoids are believed to provide antioxidant protection to lipid-rich tissues. Research suggests $\beta$-carotene may work synergistically with vitamin E $[11 ; 12]$. $\beta$-carotene accounts for $80 \%$ of the carotenoids present in S.platensis [13].

The generation of biomass by photosynthetic S.platensis cultures depend on environmental factors including nitrogen concentration, light intensity, and $\mathrm{pH}$ [14-16]. Urea as a source of nitrogen is cheaper than nitrate [17]. The aim of this study were to assess the effect of nitrogen concentration, intensity of light, and $\mathrm{pH}$ of S.platensis in culture glasses.

\section{MATERIALS AND METHODS}

\section{Test Chemical}

S. platensis was obtained from BBPBAP (Balai Besar Pengembangan Budidaya Air Payau) Company, Indonesia in form living cell. Bold bassal medium, sodium bicarbonate, urea, aquadest, ascorbic acid, acetone, 1,1-diphenyl-2picryl-hydrazyl free radicals, methanol, acetonitrile, dichloromethane.

\section{Culture Condition}

The S. Platensis cultures were maintained in $500 \mathrm{~mL}$ glass which is containing $300 \mathrm{~mL}$ bold bassal medium for each. Cultures was stirred by bubling air at room temperature and keep under fluorescent of 3000 lux with photoperiode dark : light $(12: 12 \mathrm{~h} / \mathrm{h})$ and sunlight for 19 days.

Productivity of biomass was calculated by measuring absorbance of cells. The absorbance of cell was determined by using spectrophotometer UV-vis (Genesys 20 Thermoscientific). The growth of the cell was cotrolled once in two days.

The optimum variation of this method was used for the next step. The following variations including the initial absorbance of cells were moderated by using spectrophotometer. The wavelength used was $560 \mathrm{~nm}$. The $\mathrm{pH}$ of the cultures were measuredby $\mathrm{pH}$ meter and continued by adding $\mathrm{NaHCO}_{3}$ gradually until gotten $\mathrm{pH} 8$ and 9 . Urea was used as a nitrogen source in this process.

\section{Antioxidant activity}

Free radical scavenging activity of different extract using acetone and acetone: methanol (1:1) from S. platensis was measured by DPPH method. In brief, $100 \mu \mathrm{L}$ of DPPH $0.1 \mathrm{mM}$ was added to $100 \mu \mathrm{L}$ S.platensis extract into 48wells microplate. The concentration of $S$. platensis was variated $(500,250,125$, dan $62.5 \mu \mathrm{g} / \mathrm{mL})$. The mixture was incubated using room temperature for $30 \mathrm{~min}$. The absorbance was measured at $517 \mathrm{~nm}$ by using spectrophotometer UV-vis (Shimadzu, Japan) [13]. The positive control used ascorbic acid and the experiment was done in triplicate [16].

\section{HPLC Measurement}

$$
\% \text { Inhibition }=\frac{\text { Ablank-Asample }}{\text { Ablank }} \times 100 \%
$$

The homogenity and the purity of $\beta$-carotene were checked by HPLC (Shimadzu L17844, Japan) reverse phase 25 $\mathrm{cm}, \mathrm{C} 18$ column with isocratic system consisted methanol: acetonitrile: dichloromethane $(10: 70: 20, \mathrm{v} / \mathrm{v} / \mathrm{v})$ at flow rate $1.0 \mathrm{ml} / \mathrm{min}$ and the column temperature was $25^{\circ} \mathrm{C}$. The identification of $\beta$-carotene was performed by comparing retention time. $\beta$-carotene was monitored at $450 \mathrm{~nm}$ with a UV-visible detector (Shimadzu, Kyoto, Japan). 


\section{RESULTS AND DISCUSSION}

The growth of Spirulina platensis

The growth of $S$. platensis cell in $300 \mathrm{~mL}$ culture using BBM standard under sunlight was showed in figure 1 . The other growth curves were the same cultural cells among different condition (figure 2-5). The higher of absorbance of cells was selected for further sudies.
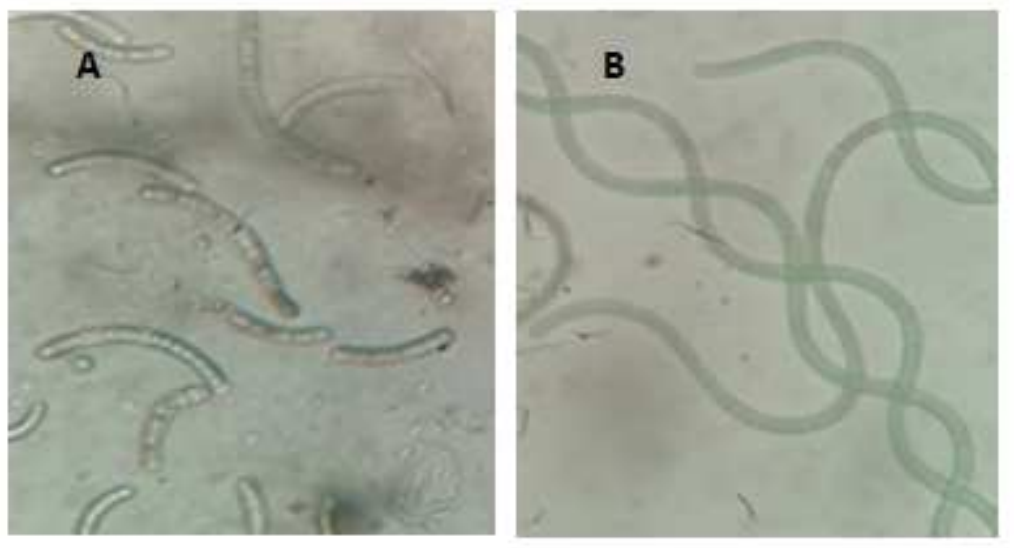

Figure 1. Morphology of S.platensis cells; S.platensis at second day (A). S. platensis at tenth day (B)

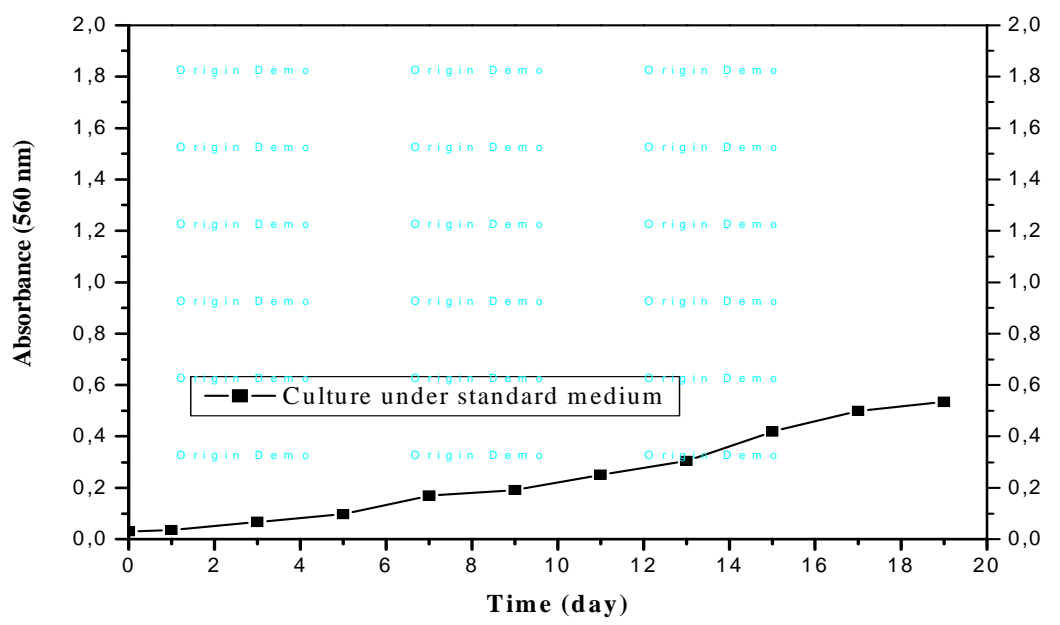

Figure 2. Shows the growth of $S$. platensis cell under sunlight using BBM standard

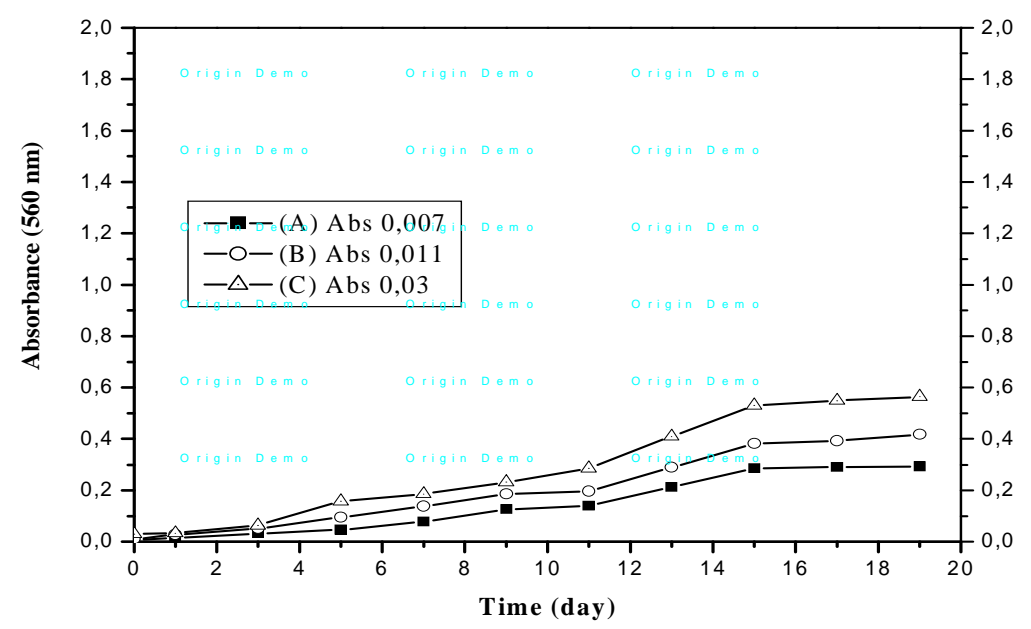

Figure 3. Effect of initial absorbance by using spectrophotometer $560 \mathrm{~nm}$. S. platensis in culture glasses under natural sunlight. (A) initial absorbancewas 0.007 ; (B) initial absorbance was $0.011 ;(C)$ initial absorbance 


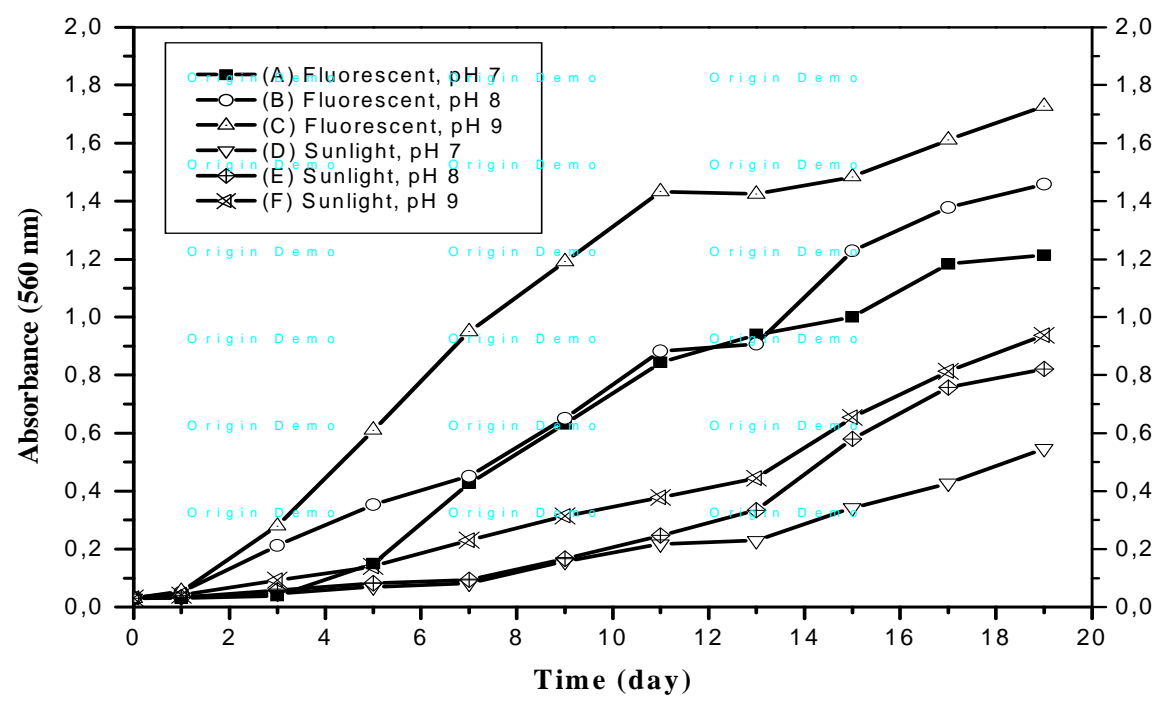

Figure 4. Effect of initial $\mathrm{NaHCO}_{3}$ concentration on $\mathrm{S}$. platensis cultivated in glass. (A-C) cultivated under fluorescent light (3000 lux); (A) culture when $\mathrm{pH}$ was 7; (B) culture when $\mathrm{pH}$ was 8; (C) culture when $\mathrm{pH}$ was 9. (D-F) cultivated under sunlight; (D) culture when pH was 7; (E) culture when $\mathrm{pH}$ was 8; (F) culture when $\mathrm{pH}$ was 9

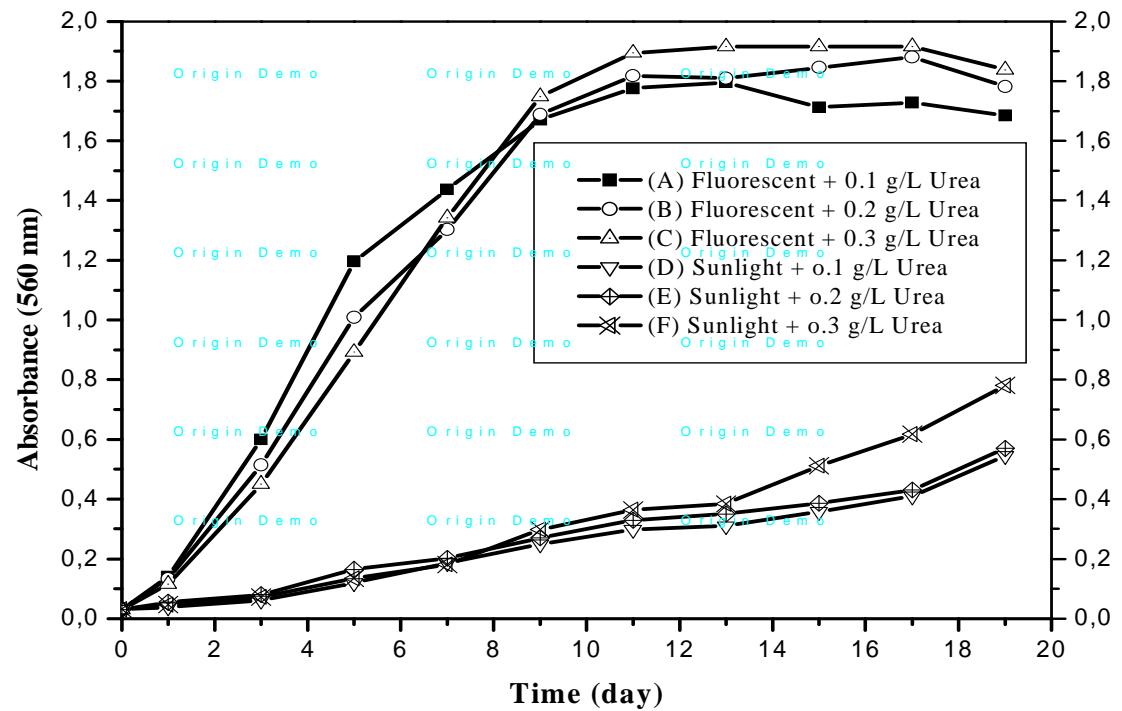

Figure 5. Effect of initial urea concentration on S.platensis cultivated in glass. (A-C) cultivated under fluorescent light (3000 lux); (A) culture using $0.1 \mathrm{~g} / \mathrm{L}$ of urea; (B) culture using $0.2 \mathrm{~g} / \mathrm{L}$ of urea (C) culture using $0.3 \mathrm{~g} / \mathrm{L}$ of urea. (D-F) cultivated under sunlight; (D) culture using $0.1 \mathrm{~g} / \mathrm{L}$ urea; (E) culture using $0.2 \mathrm{~g} /$ of urea $(\mathrm{F})$ culture using $0.3 \mathrm{~g} / \mathrm{L}$ of urea

Culture of S.platensis was grown in modified medium various urea which was each containing nitrogen. After 9 days of cultivation at 3000 lux fluorescence light, the absorbance increased up to 1.7 and 0.25 under sunlight respectively (Fig. 5). Light intensity was an important factor to maximize the conversion of incident light energy to algae biomass. Zainul et al reported (2015) light intensity, in order to combination of, from indoors light (sunlight enter to the room) and illumination of room fluorescence light, which intensity region between 774-2000 lux(18), lower than 3000 lux fluorescence light.

\section{Antioxidant Test}

The S. platensis acetone: methanol (1:1) extract of this microalgae showed better antioxidant potential when compare to $S$. platensis acetone extract. Antioxidant acivities of various S.platensis extract were studied by 1,1diphenyl-2-picryl-hydrazyl (DPPH) free radicals scavenging method as showed in figure 6. 


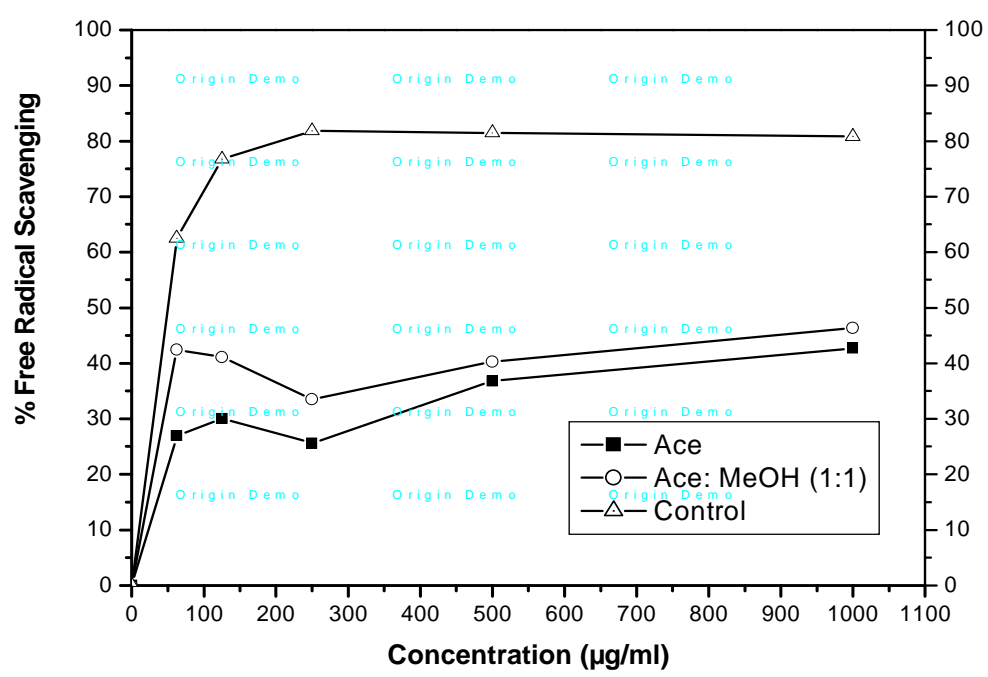

Figure 6. Effect of initial urea concentration on S.platensis and antioxidant acivities

\section{HPLC analysis of $\beta$-carotene}

The carotenoid compound especially $\beta$-carotene obtained from $\mathrm{S}$. platensis produced several major peaks which were separated within $23.08 \mathrm{~min}$ (Figure 7.A) and $24.42 \mathrm{~min}$ (Figure 7.B) through a C18 column showed the available $\beta$-carotene. The detectable of $\beta$-carotene and other carotenoid undetectable were showed (Figure 7)

The purity calculated as the percentage of the $\beta$-carotene peak area was 2.58 and retention time was 23.08 whereas the acetone ectract displayed the highest sample area and produced $1.32 \%$ of $\beta$-carotene out of total biomass (Figure 7.A).
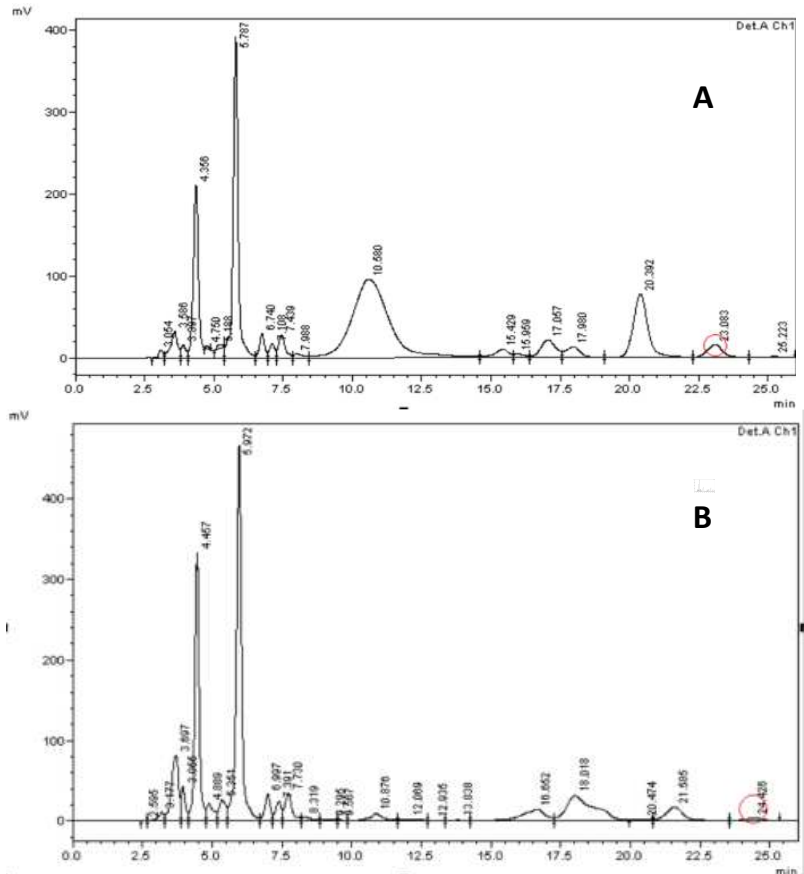

Figure 7. HPLC profile of total carotenoid extract from S. platensis extracted using acetone (Figure 7.A) S. platensis extracted using acetone: methanol (Figure 7.B)

\section{CONCLUSION}

The carotenoids are widely used as colorants, they also play an important role as a precursors of vitamin A and antioxidant. The optimum growth of Spirulina platensis was in $0.3 \mathrm{~g} / \mathrm{L}$ urea, pH 9 at fluoresense light (3000 lux). Antioxidant acivity of various spirulina extract was studied by 1,1-diphenyl-2-picryl-hydrazyl (DPPH) free radicals scavenging method. The Spirulina radicals scavenging activity of acetone:methanol (1:1) extract was 46.39 \% . The 
acetone:methanol (1:1) extract showed better antioxidant activity than acetone extract. The $\beta$-carotene was determined using HPLC in a silica gel column with dichloromethane, acetonitrile, methanol (20:70:10, v/v/v) as a mobile phase. The acetone extract displayed the highest sample area and produced $1.32 \%$ of $\beta$-carotene out of total biomass.

\section{REFERENCES}

[1] B H, JMC G. 1999. Oxford University Press 3rd ed

[2] JP K. 1993. Crit Rev Toxicol 23:21-48

[3] Christen WG, Glynn RJ, Chew EY ea. 2010. Ophthalmology 117:1163-8

[4] Christen WG, Glynn RJ, Sesso HD ea. 2010. Archives of Ophthalmology 128:139

[5] Chun OK, Floegel A, Chung SJ ea. 2010. Journal of Nutrition 140:317-24

[6] Cook NR, Albert CM, Gaziano JM ea. 2007. Archives of Internal Medicine: 167:1610-8

[7] Crowe FL, Roddam AW, Key TJ ea. 2011. European Heart Journal 32:1235 -43

[8] Davies MJ, Fu S, Wang H, RT D. 1999. Free Radic Biol Med 27:1151-61

[9] Palla JC, F b. 1969. Acad. Sc. Paris, t.269 1704-7

[10] Sies Hea. 1992. Ann NY Acad Sci 669:7-20

[11] Jacob RA. 1995. Nutr Res 15:755-66

[12] Sies H, W A. 1995. Am J Cln Nutr: 62:1315S-21

[13] Vaidyaratnam, PS V. 2002. Orient longman publishing house, Kottakkal-India 146

[14] Chen F, M J. 1991. J. Appl. Phycol 3:203 - 9

[15] Hu Q, Kurano N, Kawachi M, I. I, S M. 1988. Appl.Microbiol. Biotechnol 49:655 - 62

[16] Jimenez C, FX N. 1991. J. Appl. Phyco 3

[17] Danesi EDG, Rangel CO, Carvalho JCM, S S. 2002. Biomass and bioenergy 23:261-9

[18]Zainul R, Alif A, Aziz H, Yasthopi A, Arief S, Syukri. 2015. Journal of Chemical and Pharmaceutical Research 7(11):57-67 